\title{
Incoming Editor's Column: \\ Ch-ch-ch-ch-changes \\ (turn and face the strain)
}

G reetings ITAL readers. I'm writing this in late September, as the Boston Red Sox attempt to back their way into the Major League Baseball postseason after blowing a 9-game lead over Tampa Bay in a major-league September meltdown of epic proportions. [Red Sox fans are prone to hyperbole, but in this case no hyperbole is needed: this meltdown really is epic.] It's down to the last game of the season, and like many Red Sox fans, I'm hopeful but not optimistic. The fate of the 2011 Red Sox will be old news by the time this appears in print, though: as I'm coming to learn, the wheels of scholarly publishing continue to turn ever so slowly, unless forced to do otherwise. Which brings me to why I'm taking on the role of editor of ITAL. On one hand, I'm fortunate to be taking on the editorship of a journal that quite clearly has been stewarded with care, dedication, and attention by my predecessors. I've spent quite a few hours recently in the Z678.9 section of my library's stacks, perusing three decades of back volumes of ITAL and its predecessor, the Journal of Library Automation. There's an impressive body of scholarly and informational output on library automation and related topics, from the sublime ("To Boolean or not to Boolean?" September 1983), to the not-so-sublime ("The Effects of Baud Rate, Performance Anxiety, and Experience in Online Bibliographic Searches," March 1990), to the sentimental ("Floppies to Pass the Billion-Dollar Level in '84." September 1982), to the déjà-vu-all-over-again ("LS2000-The Integrated Library System for OCLC," June 1984). Overall, I'd have to say there's a solid foundation to build on, plus plenty of good content in the pipeline, and it would be easy to continue on in the same vein.

But that's not why I'm here. I'm fortunate to be taking on the role of editor as ITAL faces significant changes. In his inaugural editorial for ITAL in March 2005, then-incoming editor John Webb articulated a number of worthy goals for ITAL, to both broaden and deepen the content of the journal and the demographic of the authors contributing to it. One goal in particular, though, strikes me (in hindsight of course) as problematic: "I hope to . . . facilitate the electronic publication of articles without endangering - but in fact enhancing - the absolutely essential financial contribution that the journal provides to the association." Anyone who has observed the struggles of the newspaper industry in recent years or been involved in the shift towards e-only in the world of academic/scholarly journals will not be surprised to learn that, in the intervening years since John wrote his column and ITAL has continued in print plus electronic form, revenues (primarily from subscriptions and advertising) have steadily declined while production and distribution costs have not, resulting in an increasing annual subsidy from ALA/LITA to support the publication. As a result, I've been tasked with exploring a new publication model for ITAL: open access and electronic only. Plans for-and the timing of — this transition are still being developed as I write this, but should be finalized before "my" first issue is published in March 2012.

There is much about ITAL that will not change even if the publication format does. A primary focus of the journal will continue to be to solicit and publish high-quality, peer-reviewed papers covering a broad array of topics related to the design, application, and use of technology in libraries. Changes I would like to see include making ITAL more timely and more relevant to the day-to-day work interests of many of its readers. I'd like to add more topical, current, and informational content to ITAL without negatively impacting its traditional role as a publication vehicle for librarians in tenure-track positions. ITAL in an e-only format also needs to provide easy and transparent ways for readers to be informed when new content is published and to offer advice, criticism, and commentary to help improve ITAL. I look forward to your feedback as ITAL moves in a new direction, about which I'm both hopeful and optimistic.

I would like to offer my sincere thanks to the outgoing editor of ITAL, Marc Truitt, who has been both helpful and gracious during this editorial transition. Marc is passionate about ITAL and its legacy, and I hope he'll see the future ITAL as a worthy successor to, rather than an unfortunate break from, the journal he's stewarded for the past several years.

Bob Gerrity (robert.gerrity@bc.edu) is Associate University Librarian for Information Technology, Boston College Libraries, Chestnut Hill, Massachusetts. 